\title{
PERSEPSI MASYARAKAT TERHADAP KEBERADAAN HUTAN MANGROVE DI DUSUN SETINGGA ASIN DESA SEBUBUS KECAMATAN PALOH KABUPATEN SAMBAS
}

\author{
(Community Perception On The Existence Of Mangrove Forests In Hamlet Setingga Asin, \\ Paloh Sub-District, Sambas Regency)
}

\author{
Suraimah, Eddy Thamrin, Iskandar AM \\ Fakultas Kehutanan Universitas Tanjungpura Pontianak. J1. Daya Nasional Pontianak 78124 \\ E-mail: suraimahsuraimah04439@gmail.com
}

\begin{abstract}
Mangrove forests are tropical coastal vegetation communities, which are dominated by several types of mangrove trees that are able to grow and develop in muddy coastal tidal areas. In order to preserve the biological and ecological functions of the mangrove forest ecosystem, a rational approach is needed in which a rational approach in its utilization involves communities around the area. Hamlet of Setingga Asin Sebubus Village, Paloh Subdistrict, Sambas Regency is one of the hamlets that has a mangrove forest area. The majority of the hamlet Setingga Asin people live as farmers, entrepreneurs and fishermen. People around the forest use it as additional livelihoods such as searching for shrimp, crabs, shellfish, kepah and nipah as the main ingredients for making roofs. The existence of the relationship between the community and the existence of mangrove forests raises the perception of the community in an effort to maintain and preserve the existence of the mangrove forest itself. Therefore, this study aims to determine the public perception of the existence of mangrove forests in Hamlet of Setingga Asin, Sebubus Village, Paloh Subdistrict, Sambas Regency and to know the factors that influence people's perceptions. The study used a survey method with interview techniques for 73 family heads in Hamlet Setingga Asin. Sampling of respondents is done by purposive sampling technique. The data analysis used was descriptive analysis and inferential analysis of the Kendall Tau correlation. The results showed that community perceptions of the existence of mangrove forest in hamlet Setingga Asin, Sebubus Village, Paloh Subdistrict, Sambas Regency tend to be neutral, this is because the community basically realizes that they depend on the surrounding mangrove forest's biological resources. However, the community does not understand that these resources need to be managed sustainably so that the benefits can be obtained sustainably.
\end{abstract}

Keywords: community perception, conservation, mangrove, utilization.

\section{PENDAHULUAN}

Hutan mangrove merupakan komunitas vegetasi pantai tropis, yang didominasi oleh beberapa jenis pohon mangrove yang mampu tumbuh dan berkembang pada daerah pasang surut pantai berlumpur. Ekosistem hutan mangrove ini mempunyai sifat yang unik dan khas dengan fungsi dan manfaat yang beraneka ragam bagi manusia serta makhluk hidup lainnya. Dalam rangka melestarikan fungsi biologis dan ekologis ekosistem hutan mangrove maka diperlukan suatu pendekatan yang rasional dimana pendekatan yang rasional di dalam pemanfaatannya yang melibatkan masyarakat di sekitar kawasan. Melibatkan masyarakat dalam pengelolaan hutan mangrove merupakan 
salah satu langkah awal dalam mewujudkan pelestarian hutan mangrove yang berkelanjutan Bengen (2003) dalam Dhimas (2010).

$$
\text { Kegiatan manusia pola }
$$
pemanfaatan sumberdaya alam dan pola pembangunan dituding sebagai faktor penyebab terjadinya kerusakan pada ekosistem hutan mangrove. Tindakan manusia seperti mengambil hasil kayu dari hutan mangrove itu sendiri untuk kepentingan kesejahteraan yang nantinya akan menyebabkan terjadinya degradasi ekosistem hutan mangrove. Pola pemanfaatan yang tidak ramah lingkungan juga akan mengancam keberadaan ekosistem hutan mangrove. Demikian pula pola pembangunan yang dilakukan di daerah akan mempengaruhi kelestarian sumberdaya hutan mangrove (Gumilar, 2012).

Hutan mangrove di Dusun Setingga Asin ekosistemnya masih terjaga hal tersebut dapat dilihat dari penutupannya. Masyarakat yang berada di sekitar hutan mangrove memanfaatkannya sebagai mata pencaharian tambahan seperti mencari udang, kepiting, kerang, kepah dan nipah sebagai bahan utama pembuatan atap rumah. Adanya keterkaitan antara masyarakat dengan keberadaan hutan mangrove ini menimbulkan adanya persepsi masyarakat dalam upaya menjaga dan melestarikan keberadaan hutan mangrove karena di Dusun Setingga Asin terlihat hanya memanfaatkan hasilnya saja tanpa mengetahui dampak apa saja yang akan terjadi apabila terus menerus adanya pemanfaatan tanpa ada kelestarian, maka ekosistem yang ada di hutan mangrove tersebut akan terancam keberadaannya.

Selain memanfaatkan sebaiknya masyarakat harus ikut serta melestarikan hutan mangrove, jika keberadaan hutan mangrove di daerah tersebut mengalami kerusakan maka masyarakat setempat yang memanfaatkan keberadaan hutan mangrove akan kehilangan penghasilan tambahan dan kemudian hasil dari pendapatan sebagai nelayan akan berkurang. Pada kondisi demikian, biasanya masyarakat akan menampilkan persepsi tertentu. Menurut Slameto (2010) persepsi adalah proses yang menyangkut masuknya pesan atau informasi kedalam otak manusia, melalui persepsi manusia terus menerus mengadakan hubungan dengan lingkungannya. Hubungan ini dilakukan lewat inderanya, yaitu indera penglihat, pendengar, peraba, perasa, dan pencium. Persepsi mempunyai sifat subjektif, karena bergantung pada kemampuan dan keadaan dari masing-masing individu, sehingga akan ditafsirkan berbeda oleh individu yang satu dengan yang lain. untuk memahami seperti apa persepsi masyarakat Dusun Setingga Asin terhadap keberadaan hutan mangrove Desa Sebubus Kecamatan Paloh Kabupaten Sambas, maka penelitian ini perlu dilakukan karena belum terdapat penelitian sebelumnya yang terkait di desa tersebut. Penelitian ini bertujuan untuk mengetahui persepsi masyarakat Dusun Setingga Asin terhadap keberadaan hutan mangrove Desa Sebubus Kecamatan Paloh 
Kabupaten Sambas serta mengetahui faktor yang berhubungan antara persepsi masyarakat terhadap tingkat umur, tingkat pendidikan, tingkat pengetahuan dan tingkat kosmopolitan.

\section{METODE PENELITIAN}

Penelitian dilaksanakan di Dusun Setingga Asin terhadap keberadaan hutan mangrove Desa Sebubus Kecamatan Paloh Kabupaten Sambas. Pengambilan data di lapangan secara efektif selama 4 minggu pada tanggal 26 April sampai 26 Mei 2018. Alat yang digunakan dalam penelitian ini terdiri dari kuesioner, alat tulis-menulis, kamera, kalkulator, program komputer (SPSS 16.0 For Windows). Objek penelitian adalah masyarakat Dusun Setingga Asin terhadap keberadaan hutan mangrove Desa Sebubus Kecamatan Paloh Kabupaten Sambas. Metode pengambilan sampel responden pada penelitian ini adalah dengan teknik purposive sampling. Untuk menentukan besarnya sampel dihitung dengan rumus Slovin sebagai berikut :

$$
n=\frac{N}{1+N e^{2}}
$$

Keterangan :

$\mathrm{n}=$ Jumlah sampel responden

$\mathrm{N}=$ Jumlah populasi responden

$\mathrm{e}=$ Batas toleransi kesalahan $(20 \%)$

Tabel 1. Penilaian skor persepsi masyarakat (Assesment of community perception scores)

\begin{tabular}{ccc}
\hline No & Persepsi & Bobot Skor \\
\hline 1 & Sangat Setuju (SS) & 5 \\
2 & Setuju (S) & 4 \\
3 & Ragu-ragu/Netral (R) & 3 \\
4 & Tidak Setuju (TS) & 2 \\
5 & Sangat Tidak Setuju (STS) & 1 \\
\hline
\end{tabular}

Berdasarkan total skor dari nilai bobot masing-masing item pertanyaan selanjutnya dibuat tabel frekuensi dengan tiga kategori berdasarkan perhitungan Standar Deviasi dengan bantuan program komputer (Microsoft Excel), dengan rumus:

$$
\mathrm{SD}=\sqrt{\frac{n \sum x i^{2}-\left(\sum x i^{2}\right)}{n(n-1)}}
$$

Keterangan :

$S D=$ Standar Deviasi $n=$ Jumlah Responden

$\chi i=$ nilai $\mathrm{x}$ ke $i$

Dengan ketentuan sebagai berikut:

1. Positif, jika persepsi $>X+S D$

2. Netral, jika netral $\mathrm{X}-\mathrm{SD}-<\mathrm{X}+\mathrm{SD}$

3. Negatif, jika negatif $<X-S D$

Tabel frekuensi persepsi masyarakat terhadap hutan mangrove di Dusun Setingga Asin Desa Sebubus Kecamatan Paloh Kabupaten Sambas seperti pada Tabel 2. 
Tabel 2. Persepsi Masyarakat Terhadap Keberadaan Hutan Mangrove Di Dusun Setingga Asin Desa Sebubus Kecamatan Paloh Kabupaten Sambas (Community Perception of the Existence of Mangrove Forests in Setingga Asin Hamlet, Sebubus Village, Paloh Subdistrict, Sambas District)

\begin{tabular}{clccc}
\hline No & Kategori Persepsi & Frekuensi & Persentase & Keterangan \\
\hline 1. & Positif & F1 & X1 & \\
2. & Netral & F2 & X2 & \\
3. & Negatif & F3 & X3 & \\
\hline & Jumlah & $\Sigma$ F & $\Sigma$ X & \\
\hline
\end{tabular}

Analisis deskriptif variabel persepsi dilakukan dengan analisis statistik non parameterik Chi Kuadrat $\left(\mathrm{X}^{2}\right)$ berdasarkan tabel frekuensi persepsi dengan satu variabel dan tiga kategori dengan rumus sebagai berikut (Sugiono, 2001).

$X^{2}=(x+a)^{n}=\sum_{i=1}^{k} \frac{(f o-f n)^{2}}{f n}$

Keterangan :

$\mathrm{X}^{2}$ : Chi Kuadrat

fo : Frekuensi yang diobservasi

$\mathrm{fn}$ : Frekuensi yang diharapkan $(\mathrm{n} / \mathrm{k})$

Data yang dikumpulkan dianalisis dengan analisis deskriptif dan analisis inferensial. Analisis deskriptif digunakan untuk menganalisa data dengan cara mendeskripsikan atau menggambarkan data yang telah terkumpul sebagaimana adanya tanpa bermaksud membuat kesimpulan yang berlaku untuk umum atau generalisasi (Sugiyono, 2004) sedangkan analisis inferensial digunakan untuk menganalisis data sampel dengan maksud membuat kesimpulan yang berlaku umum atau generalisasi (Idrus,
2009). Analisis inferensial digunakan untuk melihat hubungan variabel bebas terhadap variabel terikat. Variabel terikat dalam penelitian ini adalah persepsi masyarakat Dusun Setingga Asin terhadap keberadaan hutan mangrove Desa Sebubus Kecamatan Paloh Kabupaten Sambas sedangkan variabel bebasnya adalah tingkat umur, tingkat pendidikan, tingkat pengetahuan dan tingkat cosmopolitan. Model analisis inferensial yang digunakan dalam penelitian ini adalah uji statistik non parametrik korelasi Kendall Tau dengan bantuan program komputer (SPSS 16.0 For Windows).

\section{HASIL DAN PEMBAHASAN}

Berdasarkan hasil pengamatan terhadap 73 responden, diperoleh kategori frekuensi persepsi responden terhadap keberadaan hutan mangrove yakni (1)persepsi positif sebanyak 10 responden $(13,70 \%)$, (2) persepsi netral sebanyak 53 responden $(72,60 \%)$ dan (3) persepsi negatif sebanyak 10 responden (13,70\%). Frekuensi persepsi responden terhadap keberadaan hutan mangrove seperti yang disajikan pada Tabel 3 berikut. 
Tabel 3. Frekuensi responden berdasarkan persepsi terhadap keberadaan hutan mangrove Dusun Setingga Asin Desa Sebubus (Frequency of respondents based on perceptions of the existence of mangrove forests in Hamlet of Setingga Asin Sebubus Village)

\begin{tabular}{cccc}
\hline No & Persepsi & Frekuensi & Persentase (\%) \\
\hline 1 & Positif & 10 & 13,70 \\
2 & Netral & 53 & 72,60 \\
3 & Negatif & 10 & 13,70 \\
\hline & Jumlah & 73 & 100 \\
\hline
\end{tabular}

Berdasarkan Tabel 3 dan hasil uji statistik deskriptif dapat diinterpretasi bahwa dari 73 responden, sebagian besar (72,60\%) cenderung memiliki persepsi netral terhadap hutan mangrove Desa Sebubus. Hal ini disebabkan karena pada dasarnya masyarakat menyadari bahwa dirinya bergantung hidup pada sumber daya hayati hutan. Namun, masyarakat tidak memahami jika sumber daya tersebut perlu dikelola secara lestari agar dapat dimanfaatkan secara berkelanjutan.

Persepsi netral masyarakat terhadap keberadaan hutan mangrove juga disebabkan karena penilaian masyarakat terhadap manfaat hutan mangrove dari segi ekonomi lebih besar dibandingkan manfaat lainnya. Manfaat lain tersebut bisa berupa dari segi ekologi, sosial, budaya dan politik. Dari segi sosial dan politik, masyarakat tidak mengetahui secara pasti kebijakan pemerintah dalam hal pengembangan atau pengelolaan hutan mangrove tersebut, terutama di masa yang akan datang. Nilawati (2013) menjelaskan bahwa apabila persepsi seseorang positif terhadap suatu hal, maka pengambilan keputusan pun akan selaras dengan persepsi tersebut ataupun sebaliknya.

Hasil uji statistik deskriptif (Uji Chi Square) diperoleh nilai Chi Square (r) hitung pada taraf kepercayaan $95 \%$ sebesar
41,62 dan nilai Chi Square tabel sebesar 5,99 ( $\mathrm{r}$ hitung $>\mathrm{r}$ tabel). Berdasarkan hasil uji statistik deskriptif dapat disimpulkan bahwa terdapat perbedaan signifikan frekuensi persepsi masyarakat terhadap keberadaan hutan mangrove di Dusun Setingga Asin Desa Sebubus Kec. Paloh Kab. Sambas (Ha diterima dan Ho ditolak).

Pada dasarnya masyarakat yang memiliki persepsi netral ini mau dan memperhatikan setiap informasi tentang keberadaan hutan Mangrove Dusun Setingga Asin Desa Sebubus. Namun, masyarakat tidak merespon atau memberikan jawaban apabila ditanya mengenai bagaimana peran serta masyarakat dalam pengelolaan atau pelestarian hutan mangrove sekitar, kemudian masyarakat tersebut juga tidak memiliki inisiatif mengajak orang lain untuk terus menjaga hutan mangrove agar dapat berfungsi sebagaimana mestinya. Dalam arti masyarakat ini tidak mau bertanggung jawab atau akan membiarkan saja segala sesuatu dengan segala resiko di masa yang akan datang.

\section{Hubungan Variabel Terikat dan Variabel Bebas}

Hasil uji statistik korelasi Kendall Tau untuk mengetahui hubungan satu veriabel terikat dan 3 variabel bebas seperti disajikan pada Tabel 4 berikut: 
Tabel 4. Hasil Uji Statistik Korelasi Kendall Tau Hubungan Variabel Terikat dengan Variabel Bebas (Statistical Test Results of Kendall Tau Correlation of Variable Relations Bound with Free Variables)

\begin{tabular}{llcccc}
\hline & & \multicolumn{3}{c}{ Persepsi } & Keterangan \\
\cline { 3 - 4 } No & Variabel & $\mathrm{N}$ & $\begin{array}{c}\text { Correlation } \\
\text { Coefficient }\end{array}$ & $\begin{array}{c}\text { Sig. } \\
(2-\text {-tailed })\end{array}$ & \\
\hline 1. & Pendidikan & 73 & 0.305 & 0.001 & Signifikan \\
2. & Pengtahuan & 73 & 0.343 & 0.000 & Signifikan \\
3. & Kosmopolitan & 73 & -0.368 & 0.000 & Signifikan \\
\hline
\end{tabular}

\section{Hubungan Persepsi Masyarakat dengan Tingkat Pendidikan}

Hasil uji statistik korelasi Kendall Tau antara persepsi masyarakat Dusun Setingga Asin terhadap keberadaan hutan mangrove Desa Sebubus dengan tingkat pendidikan diperoleh nilai Sig.(2-tailed) 0,001 lebih kecil dari taraf signifikan 5\% atau nilai Sig 0,001<0,05 dengan nilai koefisien korelasi positif sebesar 0,305. Disimpulkan bahwa terdapat hubungan yang signifikan antara persepsi masyarakat terhadap keberadaan hutan mangrove Dusun Setingga Asin Desa Sebubus dengan tingkat pendidikan masyarakat $(\mathrm{Ha}$ diterima dan Ho ditolak). Hal ini dikuatkan oleh penelitian Setiawan (2017) yang menyatakan bahwa tingkat pendidikan berpengaruh signifikan terhadap persepsi masyarakat.

Nilai koefisien korelasi positif menunjukkan bahwa semakin positif atau tinggi pendidikan masyarakat, maka persepsi masyarakat terhadap keberadaan hutan mangrove Dusun Setingga Asin Desa Sebubus akan cenderung netral atau positif. Pendidikan formal merupakan salah satu indikator sosial yang merupakan tolak ukur untuk menentukan indeks kemajuan pembangunan suatu negara dan juga merupakan satu-satunya sistem pendidikan yang mendapat pengakuan secara administrasi (universal) sebagai indikator tingkat pengetahuan dan keahlian seseorang (Sarah, 2013).

Berdasarkan hasil pengamatan dari 73 sampel terdapat 34 responden dilapangan bahwa frekuensi tingkat pendidikan masyarakat sebagian besar (46,58\%) rata-rata berpendidikan SD maupun tidak bersekolah, dengan persepsi masyarakat terhadap keberadaan hutan mangrove cenderung netral. Berdasarkan persepsi pendidikan masyarakat menyebabkan masyarakat kurang memiliki kesadaran yang cukup dalam upaya pelestarian hutan (Ilyas, et al 2012) dalam Masria (2015). Salah satu diantara faktor penyebab rendahnya tingkat pendidikan masyarakat terjadi karena kurangnya sarana pendidikan di Desa Sebubus, teruntuk dusun Setingga Asin itu sendiri masih belum memiliki sarana pendidikan. Mamuko, et al (2016) dalam Irawan (2017) mengatakan bahwa faktor pendidikan merupakan salah satu faktor sosial ekonomi yang mempengaruhi persepsi masyarakat terhadap hutan dan fungsinya, persepsi 
terhadap program rehabilitas hutan dan lahan, serta tingkat partisipasi.

\section{Hubungan Persepsi Masyarakat dengan Tingkat Pengetahuan}

Hasil uji statistik korelasi Kendall Tau antara persepsi masyarakat terhadap keberadaan hutan mangrove Dusun Setingga Asin Desa Sebubus dengan tingkat pengetahuan masyarakat diperoleh nilai Sig.(2-tailed) 0,000 lebih kecil dari taraf signifikan 5\% atau nilai Sig $0,000<0,05$ dengan koefisien korelasi positif sebesar 0,343. Disimpulkan, bahwa terdapat hubungan yang signifikan antara persepsi masyarakat terhadap keberadaan hutan mangrove Dusun Setingga Asin Desa Sebubus dengan tingkat pengetahuan masyarakat (Ha diterima dan Ho ditolak). Persepsi masyarakat didukung oleh pengetahuan masyarakat tentang lingkungan dan pentingnya hutan mangrove bagi kehidupan masyarakat seperti dalam peningkatan taraf ekonomi baik bagi diri sendiri maupun keluarga (Nurhayati, 2018). Nilai koefisien korelasi positif menunjukkan bahwa semakin positif atau tinggi tingkat pengetahuan masyarakat, maka persepsi masyarakat terhadap keberadaan hutan mangrove Dusun Setingga Asin Desa Sebubus akan cenderung netral atau positif.

Berdasarkan olahan data primer hasil pengamatan di lapangan diperoleh kategori frekuensi tingkat pengetahuan masyarakat Dusun Setingga Asin Desa Sebubus Kecamatan Paloh Kabupaten Sambas dengan kategori tinggi sebanyak 7 responden (9,59\%), kategori sedang sebanyak 58 responden $(79,45 \%)$ dan kategori rendah sebanyak 8 responden $(10,96 \%)$. Dengan demikian dapat disimpulkan bahwa dari 73 responden penelitian diperoleh tingkat pengetahuan terbanyak dengan kategori sedang. Ningtyas (2015) dalam penelitiannya mengatakan bahwa semakin tinggi pengetahuan seseorang maka akan semakin tinggi pula persepsi positif seseorang.

Pengetahuan dipengaruhi oleh faktor pendidikan formal, pengetahuan sangat erat hubungannya dengan pendidikan, di mana diharapkan bahwa dengan pendidikan yang tinggi maka orang tersebut akan semakin luas pula pengetahuannya. Akan tetapi, perlu ditekankan bukan berarti seseorang yang berpendidikan rendah mutlak berpengetahuan rendah pula, hal ini mengingat bahwa peningkatan pengetahuan tidak mutlak diperoleh dari pendidikan formal saja, akan tetapi dapat diperoleh dari pendidikan non formal dan keterbukaan masyarakat dalam mencari atau menerima informasi baru.

Pada dasarnya, masyarakat senang jika menerima informasi baru dari berbagai sumber, baik secara formal maupun informal. Namun, kurangnya sumber informasi seperti surat kabar, radio, jaringan internet untuk media sosial, penyuluhan atau sosialisasi dari dinas terkait di dusun tersebut menjadi salah satu faktor tingkat pengetahuan masyarakat terhadap hutan mangrove di Dusun Setingga Asin Desa Sebubus hanya berada pada kategori sedang. 


\section{Hubungan Persepsi Masyarakat dengan Tingkat Kosmopolitan}

Hasil uji statistik korelasi Kendall Tau antara antara persepsi masyarakat terhadap keberadaan hutan mangrove Dusun Setingga Asin Desa Sebubus dengan tingkat kosmopolitan masyarakat diperoleh nilai Sig.(2-tailed) 0,000 lebih kecil dari taraf signifikan $5 \%$ atau nilai Sig $0,000<0,05$ dengan koefisien korelasi negatif sebesar $-0,368$. Disimpulkan, bahwa terdapat hubungan yang signifikan antara persepsi masyarakat terhadap keberadaan hutan mangrove Dusun Setingga Asin Desa Sebubus dengan tingkat kosmopolitan masyarakat (Ha diterima dan Ho ditolak). Sejalan dengan penelitian Nutriawani (2017) menjelaskan bahwa tingkat kosmopolitan masyarakat berpengaruh positif terhadap persepsi masyarakat. Nilai koefisien korelasi negatif menunjukan bahwa semakin negatif atau rendah tingkat kosmopolitan masyarakat, maka persepsi masyarakat Dusun Setingga Asin terhadap keberadaan hutan mangrove Dusun Setingga Asin Desa Sebubus akan cenderung negatif.

Berdasarkan pengamatan, tingkat kosmopolitan yang sedang tersebut disebabkan karena sebagian besar masyarakat Dusun Setingga Asin terhitung hampir setiap hari senang menonton berita baru di televisi. Namun, untuk mencari informasi baru terkait hutan mangrove sangat jarang masyarakat lakukan dan jaringan internet yang sangat minim sekalali untuk mendapatkan atau memperoleh informasi dari luar. Kurniawan (2008) menjelaskan bahwa tingkat kosmopolitan adalah kemauan, keterbukaan atau kemampuan seseorang untuk melakukan perjalanan keluar desa atau komunitasnya, frekuensi aktivitas seseorang menghadiri pertemuan resmi atau tidak resmi, akses pada benda-benda yang memungkinkan responden dapat berinteraksi dengan orang-orang yang berada di luar komunitasnya seperti, kepemilikan telepon seluler, kendaraan bermotor, televisi, sumber informasi seperti koran/majalah.

Ratnawati,et al (2014) menjelaskan bahwa semakin tinggi tingkat kosmopolitan yang ada, maka masyarakat akan memiliki kecenderungan yang besar untuk dapat menerima suatu objek atau suatu hal yang bersifat membangun.

\section{Kesimpulan}

1. Persepsi masyarakat terhadap keberadaan hutan mangrove di Dusun Setingga Asin Desa Sebubus cenderung netral $(72,60 \%)$.

2. Terdapat hubungan yang signifikan antara persepsi masyarakat terhadap keberadaan hutan mangrove di Dusun Setingga Asin Desa Sebubus dengan tingkat pendidikan, tingkat pengetahuan dan tingkat kosmopolitan, antara lain:

a. Hasil persepsi masyarakat terhadap keberadaan hutan mangrove Dusun Setingga Asin dengan tingkat umur diperoleh nilai koefisien korelasi negatif sebesar -0,079, disimpulkan bahwa tidak terdapat hubungan 
yang signifikan antara kedua hal tersebut.

b. Hasil persepsi masyarakat terhadap keberadaan hutan mangrove Dusun Setingga Asin dengan tingkat pendidikan diperoleh nilai koefisien korelasi positif sebesar 0,305 , disimpulkan bahwa terdapat hubungan yang signifikan antara kedua hal tersebut.

c. Hasil persepsi masyarakat terhadap keberadaan hutan mangrove Dusun Setingga Asin dengan tingkat pengetahuan diperoleh nilai koefisien korelasi positif sebesar 0,343 , disimpulkan bahwa terdapat hubungan yang signifikan antara kedua hal tersebut.

d. Hasil persepsi masyarakat terhadap keberadaan hutan mangrove Dusun Setingga Asin dengan tingkat kosmopolitan diperoleh nilai koefisien korelasi negatif sebesar 0,368, disimpulkan bahwa terdapat hubungan yang signifikan antara kedua hal tersebut.

\section{Saran}

1. Adanya tingkat persepsi yang netral dari masyarakat dalam melestarikan fungsi hutan mangrove hendaknya di respon oleh pihak Pemerintah Kecamatan Paloh Kabupaten Sambas dengan megoptimalkan pengelolaan pada hutan mangrove dan memberikan penyuluhan tentang manfaat dan fungsi dari hutan mangrove sehingga secara langsung maupun tidak langsung akan menimbulkan ketertarikan (perhatian) masyarakat terhadap hutan mangrove di Dusun Setingga Asin.

2. Peningkatan variabel pendidikan bisa dilakukan dengan upaya memberikan penyadartahuan akan pentingnya pendidikan formal maupun informal kepada masyarakat. Sedangkan peningkatan variabel pengetahuan dan kosmopolitan bisa dilakukan dengan upaya memberikan penyadartahuan akan pentingnya fungsi hutan mangrove melalui penyuluhan, sosialisasi, dan lain sebagainya. Selain itu masyarakat harus dilibatkan dalam pengelolaan hutan mangrove tersebut.

3. Diharapkan masyarakat sekitar dapat berpartisipasi dalam menjaga lingkungan hutan mangrove dan mengelola lahan yang kosong untuk pertanian maupun tambak ikan dan udang dan tidak merusak lahan seperti menebang dan membuat sarang lebah di pohon yang masih sehat.

\section{DAFTAR PUSTAKA}

Dhimas W, Asbar L. 2010. Kajian Pengelolaan Hutan Mangrove di Kawasan Konservasi Desa Mambarungan Kota Tarakan Kalimantan Timur. Fakultas Perikanan dan Ilmu Kelautan Universitas Borneo. Jurnal Saintek. Vol 2 No 1.

Gumilar I. 2012. Partisipasimasyrakat Pesisir Dalam Pengelolaan Ekosistem Hutan Mangrove Berkelanjutan Di Kabupaten Indramayu. Fakultas Perikanan Dan Ilmu Kelautan. Universitas 
Padjadjaran. Jawa Barat. Jurnal Akuatik. Vol 3 No2

Heryatna D, Sofyan Z, Harnani H. 2015. Persepsi Masyarakat Terhadap Keberadaan Hutan Keasyarakatan Di Desa Meragun Kecamatan Nanga Taman Kabupaten Sekadau. Jurnal Hutan Lestari Vol 4 No 1.

Idrus, M. 2009. Metode Penelitian Ilmu Sosial-Pendekatan Kualitatif dan Kuantitatif Edisi Kedua. Erlangga. Yogyakarta.Masria,. Golar dan Moh I. 2015.Persepsi dan Sikap Masyarakat Lokal Terhadap HutanDi Desa Labuan Toposo Kecamatan Labuan Kabupaten Donggala. Jurnal Warta Rimba Vol 3 No 2.

Nanlohy H, Aziz N.B, Ambaryanto, Sahala H. 2014. Analisis Persepsi Masyarakat Terhadap Pengelolaan Kawasan Mangrove Teluk Kotania. Jurnal Wilayah dan Lingkungan. Vol 2 No 1.

Nilawati. 2013. Hubungan Antara Persepsi dengan Sikap Orangtua Terhadap Paud Khairunnisa Seberang Padang Kecamatan Padang Selatan Kota Padang. Jurnal Spektrum Pls. Vol 1 No 1:11. 2013.

Nurhayati, Amar M, Nur A. 2018. Persepsi dan Sikap Masyarakat Terhadap Pengembangan Ekowisata Mangrove Bungkutoko Kendari. Fakultas Kehutanan dan
Ilmu Lingkungan Universitas Halu Oleo. Jurnal Ecogreen Vol 4 No 1.

Nutriwani R, Bachrun N, Joko N. 2017. Sikap Masyarakat Dusun Pasir Laut Terhadap Keberadaan Hutan Mangrove Di Dusun Pasir Laut Kecamatan Mempawah Hilir Kabupaten Mempawah. . Jurnal Hutan Lestari Vol 5 No 2.

Irawan A, Iwanuddin, Jafred E.H, Sulistya E. 2017. Analisis Persepsi dan Perilaku Masyarakat Terhadap Keberadaan Kawasan KPHP Model Poigar. Jurnal Penelitian Sosial dan Ekonomi Kehutanan. Vol 14 No 1.

Khadapi M, Gusti H, Sofyan Z. 2015. Persepsi Masyarakat Desa Sungai Awan Kanan Terhadap Keberadaan Hutan Mangrove Di Kawasan Pantai Air Mata Permai Kabupaten Ketapang. Jurnal Hutan Lestari. Vol 3 No 1.

Setiawan H, Rini P, Garsetiasih. 2017. Persepsi dan Sikap Masyarakat Terhadap Konservasi Ekosistem Mangrove Di Pulau Tanakeke Sulawesi Selatan. Jurnal Peneletian Sosial dan Ekonomi Kehutanan. Vol 14 No 1.

Slameto B. 2010. Faktor-faktor yang mempengaruhi. Jakarta: RinekaCipta.

Sugiyono. 2004. Metode Penelitian Bisnis. Bandung. CV Alfabeta. 